Article

\title{
Assessment of Maximum Possible Urbanization Influences on Land Temperature Data by Comparison of Land and Marine Data around Coasts
}

\section{Dimitrios A. Efthymiadis and Philip D. Jones *}

Climatic Research Unit, School of Environmental Sciences, University of East Anglia, Norwich, NR4 7TJ, UK; E-Mail: d.efthymiadis@uea.ac.uk

* Author to whom correspondence should be addressed; E-Mail: p.jones@uea.ac.uk; Tel.: +44-1603-592090; Fax: +44-1603-507784.

Received: 24 August 2010; in revised form: 25 November 2010 / Accepted: 2 December 2010 / Published: 6 December 2010

\begin{abstract}
Global surface temperature trends, based on land and marine data, show warming of about $0.8{ }^{\circ} \mathrm{C}$ over the last 100 years. This rate of warming is sometimes questioned because of the existence of Urban Heat Islands (UHIs). In this study we compare the rate of temperature change estimated from measurements of land and marine temperatures for the same grid squares using $5^{\circ}$ by $5^{\circ}$ latitude/longitude grid-box datasets. For 1951-2009 the 'land' average warmed by $0.02{ }^{\circ} \mathrm{C}$ decade ${ }^{-1}$ relative to the 'sea surface temperature' (SST) average. There were regional contrasts in the trends of land/sea temperature differences: the land warmed at a greater rate compared to the SST for regions north of $20^{\circ} \mathrm{S}$, but the opposite occurred further south. Given strong forcing of the climate system, we would expect the land to change more rapidly than the ocean, so the differences represent an upper limit to the urbanization effect.
\end{abstract}

Keywords: global warming; air temperature trends; urbanization

\section{Introduction}

Land-based temperature records have a number of potential inhomogeneities and biases (see discussion by Brohan et al. [1]). These include site moves, issues with exposure of the instruments (e.g., the change in the late 19 th to early 20 th century to louvred screens) and the potential effects of 
the growth of towns and cities around the sites along with the effects of land-use changes around measuring sites. Site moves have important impacts for individual locations, but as the effects across the world are essentially random, the other two factors are more important when it comes to large-scale averages (see, e.g., [2]). Exposure changes may have impacts on temperature records on a national basis (related recently to automation), but the main effects occurred much earlier (see [3]).

Numerous studies (see, e.g., the summary by Oke [4] and also Stewart [5]) have shown that urban sites are, on average, warmer than rural surroundings: this phenomenon is often referred to as the urban heat island (UHI). However, the emphasis in many studies is generally given to the largest monthly, daily, or even hourly, differences. The implication of the more comprehensive of these studies (e.g., [6-8]) is that the growth of towns and cities can impact temperature time series, but effects are spatially variable. The issue of the UHI is often combined with the issue of changes in land-use, which have occurred in many locations around the world. Arnfield [9] and Parker [10] discuss why UHIs come about in terms of changes to the energy balance (i) changes to the longwave radiation balance and to land surface albedo changes (e.g., building development, tarmac etc.) and (ii) waste heat from energy use.

For studies of the potential urban influence on global-scale temperature trends, we are not interested in extreme differences, nor in assessments of the magnitude of the UHI from individual locations or in small regions, but in changes to urban influences over periods of decades in large-area (continental to hemispheric in scale) averages based on many station records (see [10-13]). The effects of UHIs extend back to the 19th century, but in terms of long-term monitoring of large-scale temperature averages what matters is the change in any UHI through time. Jones and Lister [14], for example, show that although sites in Central London are warmer than rural locations outside the city, the rate of temperature change from centrally- and rurally-located sites has been the same since 1900. In terms of the changes in energy balance, the central London example implies that (i) has had little effect since 1900, but although (ii) has surely risen, there is no signal in urban/rural temperature differences when considered over the whole of the 20th century. Wilby et al. [15], however, show that there is a significant increase in the urban/rural temperature difference in London between 1951 and 1980, but relate this increase in the UHI over this period to regional atmospheric circulation changes which favoured stronger UHIs in the 1970s compared to the 1950s. The UHI reduced after 1980 as less favourable circulation conditions prevailed. In contrast, census data show that the population of Greater London declined by $\sim 1.4$ million people between the 1950 s and 1980s then rose by $\sim 0.8$ million to year 2008. These issues illustrate the point made by Stewart [5] that many studies do not consider all possible factors that could influence air temperatures.

Despite a number of studies (see the recent review by Parker [10]) indicating that urbanization effects on land-based large-scale temperature changes are minimal, there is a popular belief that much of the warming of the land-based temperature record is due to urbanization influences. This appears to stem from studies that indicate large UHIs on individual days or nights and subsequent unwarranted extrapolation that these values apply to long-term trends. The current value of the urbanization effect used by Brohan et al. [1] corresponds to $0.006{ }^{\circ} \mathrm{C}$ decade ${ }^{-1}$, implying there is an effect but it is an order of magnitude smaller than the long-term warming.

Parker [10] has reviewed several possible approaches to the assessment of the magnitude of any urbanization effect. One method of large-scale assessment of the effects of urbanization on surface 
temperature records would be to compare trends with totally independent estimates of temperatures from the lower troposphere (the 2LT band centered at $700 \mathrm{hPa}$, see [16]) estimated by satellites (which are available from 1979). The trend of global surface temperature from the HadCRUT3 (land and marine) dataset [1] for the period from 1979 to 2009 is $0.16{ }^{\circ} \mathrm{C} \mathrm{decade}{ }^{-1}$, while for the two satellite records (Remote Sensing Systems, RSS and University of Alabama, Huntsville, UAH, respectively, see [17] and [18]) over the same period, the trend is 0.15 and $0.13{ }^{\circ} \mathrm{C}$ decade $^{-1}$. Surface and lower tropospheric temperature variations need not necessarily agree on short timescales, but climatological expectations are that on longer timescales they should [16]. The record for comparison is now 31 years and the agreement is clearly evident in the above numbers, particularly for the RSS data.

In this study, however, we compare temperature trends from the independently produced land and marine components of the global temperature database. This provides a relatively large sample for comparisons, but again it must be borne in mind that the land and marine trends even in the same $5^{\circ}$ by $5^{\circ}$ grid-box areas need not be the same. As with the satellite records, the longer the period of comparison, the greater the likelihood that differences in the trends reflect consistent physical changes.

\section{Data and Methods}

We compare surface temperatures from the terrestrial and marine realms where the two intersect (continental coastal areas and islands). The surface temperature data come from two datasets-land (CRUTEM3, [1]) and marine (HadSST2, [19]). Both datasets provide monthly-mean temperature anomalies (from the period 1961-1990) for $5^{\circ} \times 5^{\circ}$ latitude/longitude grid-boxes, from 1850 to the present. We only use data from grid boxes that have values in both datasets. No interpolation of data to missing grid boxes is undertaken in either CRUTEM3 or in HadSST2. As the number of coastal/island grid boxes with data jointly available in the two datasets is much greater in recent decades (Figure 1a), we focus on 1951-2009. An advantage of this period is that there are no adjustments made to the SST data [19], although some have been mooted for the 1945-1960 period [20].

We calculated annual-mean and conventional seasonal averages (DJF, MAM, JJA and SON) of the CRUTEM3-HadSST2 difference. Linear trends of the temperature-difference were then calculated based on ordinary least squares, and their statistical significance was assessed using a 2-tailed Student's-t test (accounting for temporal autocorrelation effects, as suggested by Santer et al. [21]). Trends were calculated for 1951-2009, 1951-1979 and 1979-2009 provided that (a) the number of years with complete annual/seasonal data does not fall below two thirds of the full period length (i.e., at least 40 years for 1951-2009), and (b) the same condition was also met for the first and last thirds of this period. The later period (1979-2009) was specifically used for the calculation of trends as it emphasizes the recent global warming episode that started in the 1970s.

In addition to the individual grid-box analysis, regional groups of 2-7 grid boxes were combined and regional-mean time series of the CRUTEM3-HadSST2 difference calculated (see Figure 1b for the boundaries of these regions). Each region comprises grid boxes with at least 45 years of data for 1951-2009 (i.e., 75\% of the full period length). Combination of the individual grid-box series into these eighteen regional series results in continuous series for each region (names of the regions are given in Table 1). These regional series are complete as data are never missing simultaneously from all constituent grid-boxes within any region. 
Northern Extratropics, Tropical/Subtropical, and Southern Extratropics mean time series were also calculated by averaging the selected subregions that fall within these broad domains. For the Northern Extratropics domain, the CRUTEM3-HadSST2 difference time series from the Western and Eastern Mediterranean regions were initially averaged, as well as the Britain-Ireland, Southern Scandinavia and Northeast Norway regions to construct a Southern Europe and a Northern Europe mean series, respectively. Thus the Northern Extratropics mean series was derived after averaging these two European series together with the Korea-Japan, West USA-Canada and East USA - Canada regional series. For the Tropical/Subtropical and Southern Extratropics domains their mean series were calculated by simply averaging their regional series. Finally, a 'Global' time series was constructed by averaging the series of the three domains. Trends for all regions, domains and the global average are provided in Table 1 for the 1951-2009, 1951-1979 and 1979-2009 periods.

Figure 1. (Top) Coastal and island grid boxes with complete (magenta), 75-99\% (deep blue) and $<75 \%$ (light blue) coverage of overlapping data. (Bottom) as Top, but indicates in yellow the grid boxes that have been combined to create the eighteen regions (named in Table 1).

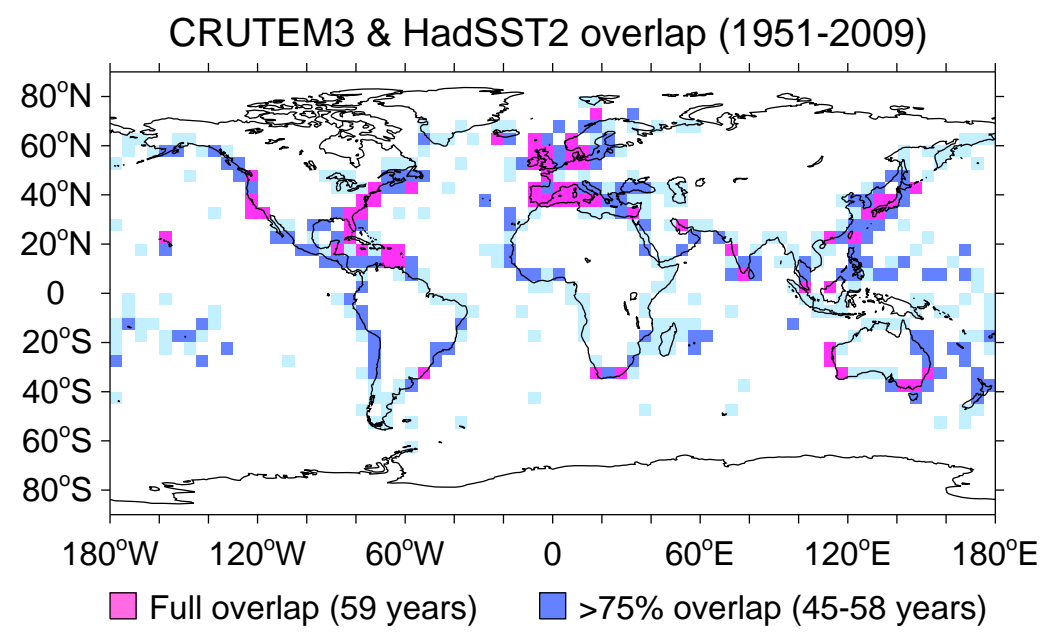

Regions selected

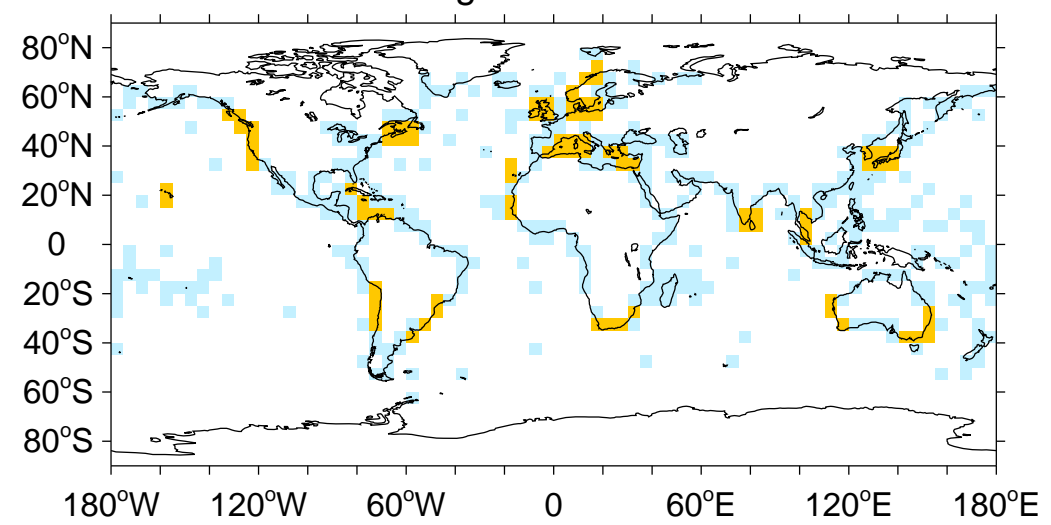


Table 1. Linear trends of temperature time series $\left({ }^{\circ} \mathrm{C} / \mathrm{decade}\right)$ for regional and wide-scale geographical domains over $1951-2009$ (left side), 1951-1979 (middle) and 1979-2009 (right side). In each cell the upper, middle, and lower numbers correspond to CRUTEM3, HadSST2 and CRUTEM3-HadSST2 difference series, respectively. Trends significant at the 95\% level are in bold. Numbers in parentheses next to the regional names indicate the number of $5^{\circ}$ by $5^{\circ}$ latitude/longitude grid boxes selected to calculate the regional time series.

\begin{tabular}{|c|c|c|c|c|c|c|c|c|c|c|c|c|c|c|c|}
\hline \multirow{2}{*}{ Region } & \multicolumn{5}{|c|}{ 1951-2009 } & \multicolumn{5}{|c|}{ 1951-1979 } & \multicolumn{5}{|c|}{ 1979-2009 } \\
\hline & ANN & DJF & MAM & JJA & SON & ANN & DJF & MAM & JJA & SON & ANN & DJF & MAM & JJA & SON \\
\hline \multicolumn{16}{|l|}{ Northern Extratropics } \\
\hline \multirow{3}{*}{ West Mediterranean (7) } & 0.22 & 0.21 & 0.34 & 0.20 & 0.14 & -0.10 & -0.24 & -0.21 & -0.24 & 0.32 & 0.35 & 0.54 & 0.58 & 0.19 & 0.19 \\
\hline & 0.10 & 0.09 & 0.15 & 0.09 & 0.07 & -0.07 & -0.08 & -0.16 & -0.10 & 0.05 & 0.26 & 0.30 & 0.42 & 0.17 & 0.18 \\
\hline & 0.12 & 0.12 & 0.19 & 0.10 & 0.07 & -0.04 & -0.16 & -0.06 & -0.15 & 0.27 & 0.09 & 0.23 & 0.16 & 0.02 & 0.01 \\
\hline \multirow{3}{*}{ East Mediterranean (4) } & 0.10 & 0.12 & 0.21 & 0.08 & 0.01 & -0.12 & 0.11 & -0.27 & -0.25 & -0.12 & 0.48 & 0.48 & 0.70 & 0.39 & 0.43 \\
\hline & 0.07 & 0.03 & 0.12 & 0.09 & 0.06 & -0.11 & -0.04 & -0.10 & -0.22 & -0.10 & 0.32 & 0.25 & 0.39 & 0.38 & 0.35 \\
\hline & 0.03 & 0.09 & 0.10 & -0.01 & -0.05 & -0.02 & 0.15 & -0.17 & -0.03 & -0.02 & 0.16 & 0.23 & 0.30 & 0.01 & 0.08 \\
\hline \multirow{3}{*}{ Britain-Ireland (4) } & 0.17 & 0.17 & 0.17 & 0.13 & 0.18 & -0.03 & -0.21 & 0.04 & -0.04 & 0.08 & 0.44 & 0.49 & 0.31 & 0.45 & 0.32 \\
\hline & 0.13 & 0.13 & 0.15 & 0.13 & 0.10 & -0.02 & -0.04 & 0.03 & 0.03 & -0.06 & 0.39 & 0.41 & 0.36 & 0.42 & 0.34 \\
\hline & 0.04 & 0.03 & 0.02 & 0.00 & 0.09 & -0.01 & -0.16 & 0.01 & 0.01 & 0.15 & 0.06 & 0.09 & -0.05 & 0.03 & -0.02 \\
\hline \multirow{3}{*}{ South Scandinavia (6) } & 0.26 & 0.35 & 0.22 & 0.11 & 0.34 & 0.03 & 0.11 & 0.03 & -0.09 & 0.09 & 0.61 & 0.59 & 0.57 & 0.42 & 0.61 \\
\hline & 0.24 & 0.37 & 0.31 & 0.12 & 0.15 & 0.07 & 0.17 & 0.10 & -0.03 & -0.02 & 0.70 & 0.80 & 0.76 & 0.61 & 0.54 \\
\hline & 0.01 & -0.03 & -0.09 & -0.01 & 0.18 & -0.04 & -0.06 & -0.07 & -0.06 & 0.11 & -0.09 & -0.21 & -0.19 & -0.19 & 0.06 \\
\hline \multirow{3}{*}{ Northeast Norway (4) } & 0.23 & 0.25 & 0.18 & 0.11 & 0.37 & -0.12 & 0.06 & 0.05 & -0.44 & -0.17 & 0.60 & 0.34 & 0.48 & 0.56 & 0.86 \\
\hline & 0.05 & 0.05 & 0.11 & 0.02 & 0.03 & -0.06 & -0.03 & 0.10 & -0.24 & -0.14 & 0.34 & $\mathbf{0 . 3 3}$ & 0.38 & 0.30 & 0.36 \\
\hline & 0.18 & 0.21 & 0.07 & 0.08 & 0.34 & -0.06 & 0.08 & -0.05 & -0.20 & -0.03 & 0.26 & 0.02 & 0.10 & 0.26 & 0.50 \\
\hline \multirow{3}{*}{ Korea-Japan (6) } & 0.17 & 0.19 & 0.11 & 0.20 & 0.19 & 0.04 & 0.04 & 0.12 & 0.03 & -0.03 & 0.37 & 0.36 & 0.23 & 0.42 & 0.51 \\
\hline & 0.10 & 0.12 & 0.07 & 0.10 & 0.13 & -0.04 & -0.08 & 0.00 & 0.01 & -0.07 & 0.30 & 0.30 & 0.22 & 0.34 & 0.37 \\
\hline & 0.07 & $\mathbf{0 . 0 7}$ & 0.04 & 0.10 & 0.06 & 0.09 & 0.12 & 0.12 & 0.02 & 0.04 & 0.07 & 0.05 & 0.01 & 0.09 & 0.14 \\
\hline \multirow{3}{*}{ West USA-Canada (7) } & 0.12 & 0.18 & 0.15 & 0.04 & 0.11 & 0.00 & 0.01 & 0.11 & -0.06 & -0.07 & 0.01 & -0.08 & 0.13 & -0.02 & -0.13 \\
\hline & 0.05 & 0.11 & 0.09 & -0.03 & 0.02 & -0.12 & -0.07 & -0.07 & -0.16 & -0.19 & -0.08 & -0.09 & 0.01 & -0.17 & -0.12 \\
\hline & 0.07 & 0.07 & 0.05 & 0.08 & 0.10 & 0.11 & 0.08 & 0.17 & 0.09 & 0.11 & 0.09 & 0.01 & 0.12 & 0.15 & -0.01 \\
\hline \multirow{3}{*}{ East USA-Canada (6) } & 0.06 & 0.06 & 0.15 & 0.07 & -0.01 & -0.24 & -0.14 & 0.16 & -0.24 & -0.58 & 0.16 & -0.12 & 0.24 & $\mathbf{0 . 3 0}$ & 0.24 \\
\hline & 0.12 & 0.13 & 0.20 & 0.13 & 0.08 & -0.22 & -0.26 & -0.07 & -0.14 & -0.23 & 0.24 & 0.10 & 0.38 & 0.25 & 0.25 \\
\hline & $-\mathbf{0 . 0 7}$ & -0.07 & -0.05 & -0.07 & -0.09 & -0.02 & 0.12 & 0.22 & -0.10 & -0.35 & -0.09 & -0.22 & -0.14 & 0.05 & -0.02 \\
\hline \multirow{3}{*}{ AVERAGE } & 0.15 & 0.17 & 0.17 & 0.11 & 0.13 & -0.07 & -0.03 & 0.04 & -0.14 & -0.12 & $\mathbf{0 . 3 0}$ & 0.23 & 0.34 & $\mathbf{0 . 3 0}$ & 0.30 \\
\hline & 0.10 & 0.12 & 0.14 & 0.08 & 0.08 & -0.10 & -0.09 & -0.04 & -0.11 & -0.12 & 0.25 & 0.23 & 0.31 & 0.23 & 0.24 \\
\hline & 0.05 & 0.05 & 0.04 & 0.04 & 0.06 & 0.03 & 0.05 & 0.07 & -0.03 & 0.00 & 0.05 & 0.01 & 0.03 & 0.07 & 0.07 \\
\hline \multicolumn{16}{|l|}{ Tropics/Subtropics } \\
\hline \multirow{3}{*}{ Northwest Africa (5) } & 0.17 & 0.14 & 0.14 & 0.18 & 0.21 & -0.04 & -0.20 & -0.14 & -0.02 & 0.14 & 0.26 & 0.27 & 0.32 & 0.23 & 0.25 \\
\hline & 0.15 & 0.13 & 0.14 & 0.16 & 0.15 & -0.04 & -0.09 & -0.09 & -0.01 & 0.05 & 0.24 & 0.17 & 0.25 & 0.30 & 0.24 \\
\hline & 0.02 & 0.01 & 0.00 & 0.01 & 0.06 & -0.01 & -0.11 & -0.05 & 0.00 & 0.09 & 0.02 & 0.11 & 0.07 & -0.08 & 0.01 \\
\hline
\end{tabular}


Table 1. Cont.

\begin{tabular}{|c|c|c|c|c|c|c|c|c|c|c|c|c|c|c|c|}
\hline \multirow{2}{*}{ Region } & \multicolumn{5}{|c|}{ 1951-2009 } & \multicolumn{5}{|c|}{ 1951-1979 } & \multicolumn{5}{|c|}{ 1979-2009 } \\
\hline & ANN & DJF & MAM & JJA & SON & ANN & DJF & MAM & JJA & SON & $\mathbf{A N N}$ & DJF & MAM & JJA & SON \\
\hline \multirow{3}{*}{ South India (4) } & 0.16 & 0.16 & 0.15 & 0.14 & 0.19 & 0.04 & 0.11 & 0.05 & 0.00 & 0.03 & 0.14 & 0.02 & 0.17 & 0.16 & 0.20 \\
\hline & 0.12 & 0.09 & 0.15 & 0.16 & 0.11 & 0.17 & 0.13 & 0.20 & 0.18 & 0.16 & 0.04 & -0.02 & 0.10 & 0.13 & 0.05 \\
\hline & 0.04 & 0.07 & -0.01 & -0.02 & 0.07 & -0.13 & -0.01 & -0.15 & -0.18 & -0.13 & 0.10 & 0.04 & 0.07 & 0.03 & 0.15 \\
\hline \multirow{3}{*}{ Thailand (3) } & 0.17 & 0.15 & 0.17 & 0.15 & 0.21 & 0.07 & 0.08 & 0.07 & 0.07 & 0.10 & 0.24 & 0.15 & 0.26 & 0.25 & 0.31 \\
\hline & 0.12 & 0.08 & 0.16 & 0.12 & 0.10 & 0.05 & -0.05 & 0.08 & 0.10 & 0.00 & 0.11 & 0.04 & 0.15 & 0.10 & 0.16 \\
\hline & 0.05 & 0.07 & 0.02 & 0.03 & 0.10 & 0.01 & 0.13 & -0.02 & -0.03 & 0.10 & 0.13 & 0.11 & 0.11 & 0.15 & 0.16 \\
\hline \multirow{3}{*}{ Hawaii (2) } & 0.15 & 0.14 & 0.19 & 0.16 & 0.11 & 0.36 & 0.40 & 0.33 & 0.37 & 0.30 & 0.01 & 0.01 & 0.07 & -0.04 & -0.05 \\
\hline & 0.04 & 0.03 & 0.04 & 0.05 & 0.03 & 0.04 & -0.02 & -0.01 & 0.07 & 0.06 & -0.03 & -0.03 & 0.03 & -0.05 & -0.08 \\
\hline & 0.11 & 0.11 & 0.14 & 0.11 & 0.08 & 0.33 & 0.41 & $\mathbf{0 . 3 4}$ & 0.31 & 0.24 & 0.04 & 0.04 & 0.04 & 0.01 & 0.02 \\
\hline \multirow{3}{*}{ Caribbean (6) } & 0.11 & 0.10 & 0.12 & 0.10 & 0.12 & -0.08 & -0.09 & -0.08 & -0.13 & -0.12 & 0.21 & 0.14 & 0.23 & 0.25 & 0.23 \\
\hline & 0.06 & 0.06 & 0.07 & 0.06 & 0.05 & -0.06 & -0.03 & -0.09 & -0.10 & -0.04 & 0.18 & 0.12 & 0.19 & 0.27 & 0.16 \\
\hline & 0.05 & 0.04 & 0.05 & 0.04 & 0.07 & -0.02 & -0.06 & 0.01 & -0.03 & -0.08 & 0.03 & 0.02 & 0.04 & -0.02 & 0.07 \\
\hline \multirow{3}{*}{ AVERAGE } & 0.15 & 0.14 & 0.15 & 0.15 & 0.17 & 0.07 & 0.06 & 0.04 & 0.06 & 0.09 & 0.17 & 0.12 & 0.21 & 0.17 & 0.19 \\
\hline & 0.10 & 0.08 & 0.11 & 0.11 & 0.09 & 0.03 & -0.01 & 0.02 & 0.05 & 0.05 & 0.11 & 0.05 & 0.14 & 0.15 & 0.11 \\
\hline & 0.05 & 0.06 & 0.04 & 0.03 & 0.08 & 0.04 & 0.07 & 0.03 & 0.01 & 0.04 & 0.06 & 0.06 & 0.07 & 0.02 & 0.08 \\
\hline \multicolumn{16}{|l|}{ Southern Extratropics } \\
\hline \multirow{3}{*}{ South Africa (4) } & 0.19 & 0.20 & 0.18 & 0.18 & 0.17 & 0.17 & 0.20 & 0.10 & 0.12 & 0.18 & 0.15 & 0.07 & 0.17 & 0.20 & 0.14 \\
\hline & 0.15 & 0.16 & 0.13 & 0.14 & 0.14 & 0.21 & 0.29 & 0.09 & 0.14 & 0.29 & 0.08 & 0.00 & 0.09 & 0.17 & 0.03 \\
\hline & 0.04 & 0.04 & 0.05 & 0.04 & 0.02 & -0.04 & -0.09 & 0.01 & -0.02 & -0.11 & 0.06 & 0.07 & 0.08 & 0.03 & 0.11 \\
\hline \multirow{3}{*}{ West Australia (3) } & 0.06 & 0.11 & 0.10 & 0.06 & -0.05 & 0.25 & 0.15 & 0.30 & 0.15 & 0.36 & -0.09 & -0.02 & 0.00 & -0.16 & -0.18 \\
\hline & 0.16 & 0.22 & 0.22 & 0.13 & 0.08 & 0.25 & 0.20 & 0.33 & 0.24 & 0.22 & 0.11 & 0.20 & 0.12 & 0.04 & 0.09 \\
\hline & -0.11 & -0.11 & -0.13 & -0.07 & -0.13 & 0.00 & -0.05 & -0.04 & -0.09 & 0.14 & -0.21 & -0.22 & -0.12 & -0.20 & -0.27 \\
\hline \multirow{3}{*}{ East Australia (5) } & 0.13 & 0.09 & 0.12 & 0.17 & 0.16 & 0.13 & 0.09 & 0.08 & 0.11 & 0.26 & 0.06 & -0.08 & 0.13 & 0.15 & 0.09 \\
\hline & 0.18 & 0.15 & 0.19 & 0.20 & 0.19 & 0.29 & 0.33 & 0.29 & 0.25 & 0.29 & 0.18 & 0.08 & 0.20 & 0.23 & 0.24 \\
\hline & -0.05 & -0.06 & $-\mathbf{0 . 0 7}$ & -0.03 & -0.03 & -0.16 & -0.24 & -0.21 & -0.14 & -0.03 & -0.12 & -0.16 & -0.06 & -0.09 & -0.15 \\
\hline \multirow{3}{*}{ North Chile (4) } & 0.00 & 0.02 & 0.05 & 0.00 & -0.05 & -0.23 & -0.24 & -0.05 & -0.24 & -0.33 & -0.06 & -0.10 & -0.07 & -0.01 & -0.08 \\
\hline & 0.16 & 0.22 & 0.11 & 0.13 & 0.14 & 0.07 & 0.00 & 0.00 & 0.09 & 0.08 & -0.14 & -0.16 & -0.21 & -0.12 & -0.08 \\
\hline & -0.16 & -0.19 & -0.07 & -0.13 & -0.19 & -0.30 & -0.24 & -0.05 & -0.33 & -0.41 & 0.08 & 0.07 & 0.15 & 0.11 & 0.00 \\
\hline \multirow{3}{*}{ Argentina-Brazil (4) } & 0.20 & 0.25 & 0.17 & 0.18 & 0.17 & 0.13 & 0.14 & 0.24 & 0.06 & 0.08 & 0.22 & 0.10 & 0.32 & 0.30 & 0.09 \\
\hline & 0.12 & 0.16 & 0.08 & 0.11 & 0.12 & 0.22 & 0.20 & 0.26 & 0.28 & 0.07 & 0.21 & 0.21 & 0.19 & 0.17 & 0.30 \\
\hline & 0.08 & 0.09 & 0.09 & 0.07 & 0.05 & -0.09 & -0.06 & -0.02 & -0.22 & 0.01 & 0.01 & -0.11 & 0.13 & 0.13 & -0.21 \\
\hline \multirow{3}{*}{ AVERAGE } & 0.11 & 0.13 & 0.12 & 0.12 & 0.08 & 0.09 & 0.07 & 0.13 & 0.04 & 0.11 & 0.05 & 0.00 & 0.11 & 0.09 & 0.01 \\
\hline & 0.15 & 0.18 & 0.15 & 0.14 & 0.13 & 0.21 & 0.20 & 0.20 & 0.20 & 0.19 & 0.09 & 0.07 & 0.08 & 0.10 & 0.11 \\
\hline & -0.04 & -0.05 & -0.02 & -0.02 & -0.06 & -0.12 & -0.14 & -0.06 & -0.16 & -0.08 & -0.03 & -0.07 & 0.03 & -0.01 & -0.10 \\
\hline \multirow{3}{*}{$\begin{array}{l}\text { GLOBAL AVERAGE } \\
\text { (Coastal) }\end{array}$} & 0.14 & 0.15 & 0.15 & 0.12 & 0.13 & 0.03 & 0.03 & 0.07 & -0.01 & 0.03 & 0.18 & 0.11 & 0.22 & 0.19 & 0.17 \\
\hline & 0.12 & 0.13 & 0.13 & 0.11 & 0.10 & 0.05 & 0.03 & 0.06 & 0.05 & 0.04 & 0.15 & 0.11 & 0.18 & 0.16 & 0.15 \\
\hline & 0.02 & 0.02 & 0.02 & 0.02 & 0.03 & -0.02 & 0.00 & 0.01 & -0.06 & -0.01 & 0.03 & 0.00 & 0.04 & 0.03 & 0.02 \\
\hline
\end{tabular}




\section{Discussion}

Figures 2a (1951-2009) and 2b (1979-2009) map the trends of the difference time series between CRUTEM3 and HadSST2. The eighteen regional time series for CRUTEM3 and HadSST2 (not shown) strongly co-vary (with high correlations, most of them in the range from 0.6 to 0.9 ) and many of them have statistically significant trends (see Table 1). The difference time series also have statistically significant trends for both periods, but in fewer cases. The marked reduction of variance when the land and marine series are differenced sometimes leads to trends of a smaller magnitude being significant in the difference time series.

Figure 2. CRUTEM3-HadSST2 trends for (a) 1951-2009 and (b) 1979-2009. The left hand plots give the trends for the annual mean, while those on the right give the same trends but only show colours where the trends are significant at the $95 \%$ level.

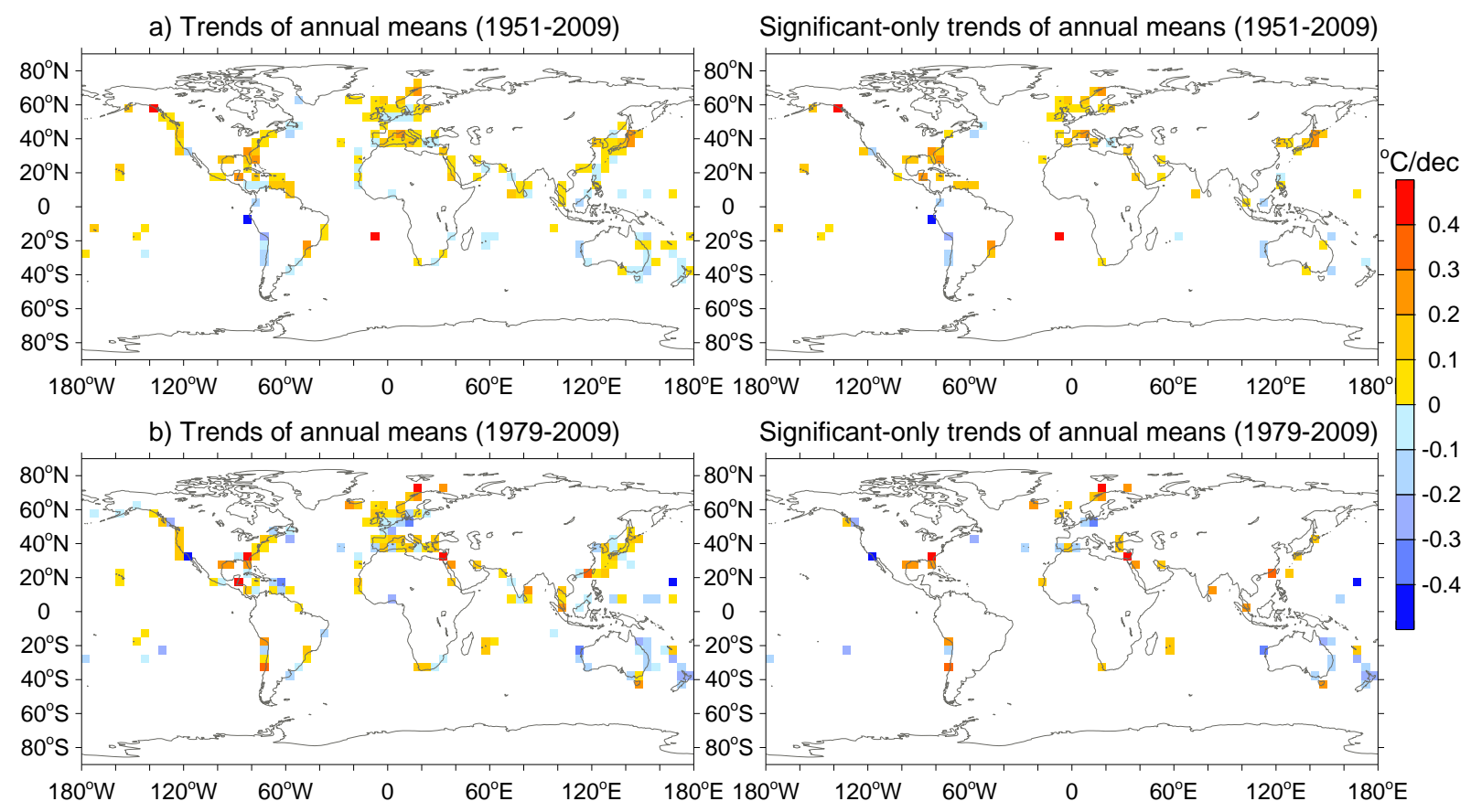

Figures $3 \mathrm{a}$ to $3 \mathrm{~d}$ show regional time series for the four domains: Northern Extratropics, Tropical/Subtropics, Southern Extratropics and 'Global'. Here we also show the separate land and ocean time series (to illustrate the strong co-variability between the two components) as well as the difference time series. The difference time series additionally show the trends for 1951-2009 and 1979-2009. Both CRUTEM3 and HadSST2 temperatures rose since the 1970s, although for some regions this hasn't been steady, particularly over the last 10 years. At the same time, the CRUTEM3/HadSST2 difference is characterized by a general increasing trend since the late 1960s/early 1970s in the Northern Extratropics and the Tropics/Subtropics, whereas for the Southern Extratropics a long-term decrease (indicated by negative linear trends) is found.

Consideration of Figures 2 and 3 and Table 1 indicates that there is much spatial variability in the trend differences between land and ocean temperatures around coastlines/islands. It is clearly impossible to generalize the results from one region to the others. Combining the time series from the regions to the larger domains produces more consistent trend differences across the seasons that make 
up the calendar year. For the Northern Extratropics and the Tropics/Subtropics the annual land/sea temperature difference trend is $0.05{ }^{\circ} \mathrm{C}$ decade $^{-1}$ for $1951-2009$, but it is $-0.04{ }^{\circ} \mathrm{C}$ decade $^{-1}$ for the Southern Extratropics. Values are similar for 1979-2009, but are slightly less positive or more negative for the first half of the data (1951-1979), particularly so for the Southern Extratropics. For the 'Global' domain the trend difference is positive $\left(0.03{ }^{\circ} \mathrm{C}\right.$ decade $\left.^{-1}\right)$ for $1979-2009$ but negative $\left(-0.02{ }^{\circ} \mathrm{C} \mathrm{decade}{ }^{-1}\right)$ for $1951-1979$. If UHIs were the sole cause of differences, the expectation should be for positive values for both periods. Instead, the results indicate the large-degree of spatial and temporal variability in the time series. The different sign of the land/sea temperature difference trends in the Southern Extratropics merits further study. Clearly, trends in one region cannot be assumed to apply to all regions.

Figure 3. (a) 'Northern Extratropics', (b) 'Tropics/Sub-Tropics', (c) 'Southern Extratropics', and (d) 'Global' average of CRUTEM3 (red), HadSST2 (in blue) and the CRUTEM3-HadSST2 difference (in black) series. Low-frequency components (10-year Gaussian filters) are over-plotted, as well as trends for the CRUTEM3-HadSST2 difference, for 1951-2009 (orange lines) and 1979-2009 (green lines). Note the different scale on the ordinate axis of the right-column set of panels.
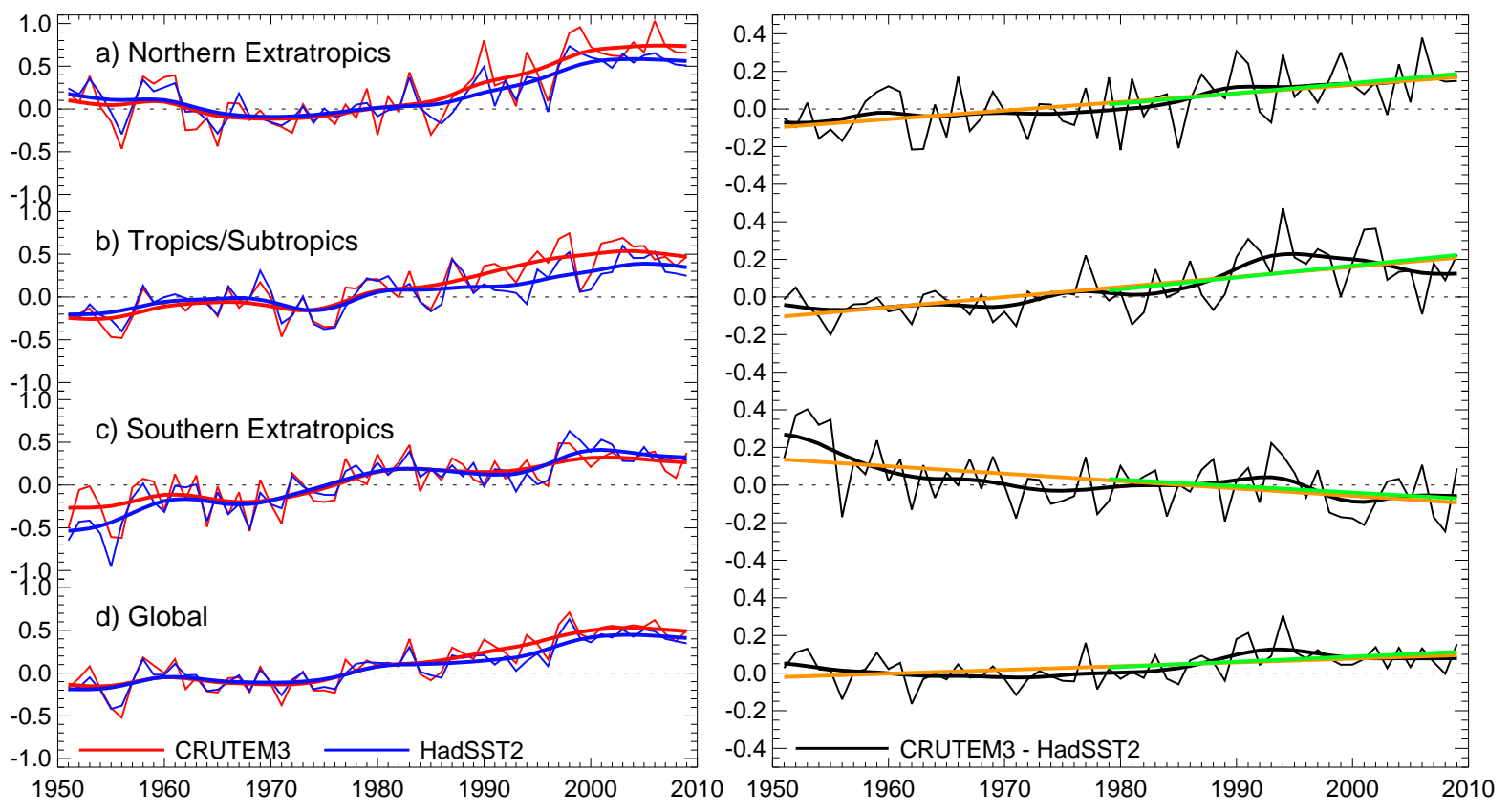

Physical considerations, such as the greater thermal capacity of the ocean and limited availability of water for evaporation over land, imply that land air temperatures should have larger trends, at least during transient climate changes, than SSTs. This is borne out by climate model simulations with continuing increases in greenhouse gases. These indicate that the land warms more rapidly than the sea [22]. Joshi et al. [23] discuss the possible mechanisms involved, though these may not be fully applicable to the coastal regions analyzed in this paper. The expectation, therefore, of greater trends over land suggests that we should treat $0.02{ }^{\circ} \mathrm{C} \mathrm{decade}{ }^{-1}$ as an upper limit of urban influence. We should also bear in mind that approximately $50 \%$ of the global population lives within $200 \mathrm{~km}$ distance from the coast [24], and this zone is indeed covered by the $5^{\circ} \times 5^{\circ}$ coastal grid-boxes of CRUTEM3 selected and analyzed. We should, consequently, expect any UHI effects on temperature records to be 
clearly manifested in the coastal regions. We have calculated the global average from all land grid cells and all ocean grid cells separately and the trends (and the CRUTEM3-HadSST2 differences) over the three different periods are not significantly different from the global averages for the coastal squares presented in Table 1, although inland grid cells exhibit an enhanced land/sea warming difference $\left(0.07^{\circ} \mathrm{C}\right.$ decade $^{-1}$ globally, for $\left.1951-2009\right)$ with stronger contrast for lands in the Northern Extratropics.

\section{Conclusions}

For the coastal and island regions assessed in this study, and for the period 1951-2009 the terrestrial regions warm by $0.02^{\circ} \mathrm{C}$ decade $^{-1}$ compared to SST data from the same $5^{\circ}$ by $5^{\circ}$ latitude/longitude grid boxes. For the more recent period of $1979-2009$ the value was $0.03^{\circ} \mathrm{C} \mathrm{decade}^{-1}$, but for the earlier period the opposite occurs (i.e., a cooling of the land relative to the sea of $0.02{ }^{\circ} \mathrm{C}$ decade $^{-1}$ though the 1951-1979 results are not statistically significant). Our approach to the assessment of urbanization effects has one potential shortcoming. This is the assumption that the two realms (land and sea) should change their temperatures at the same rate. Simple physical arguments indicate that this should be true when the climate is not being externally forced and on timescales longer than centuries. On shorter timescales, land temperatures would be expected to change more rapidly than their marine counterparts if the climate system were undergoing strong forcing (based on RCM simulations). Our estimate of the warming rate is, therefore, an upper limit, with the true value being somewhere between zero and $0.02{ }^{\circ} \mathrm{C}$ decade $^{-1}$.

\section{Acknowledgements}

This work has been supported by the U.S. Department of Energy (grant DE-FG02-98ER62601). The authors thank Tim Osborn for comments on an early draft, and two anonymous reviewers for suggestions for improvement to the manuscript.

\section{References}

1. Brohan, P.; Kennedy, J.J.; Harris, I.; Tett, S.F.B.; Jones P.D. Uncertainty estimates in regional and global observed temperature changes: A new data set from 1850. J. Geophys. Res. 2006, 111, D12106:1-D12106:21.

2. Jones, P.D.; Wigley, T.M.L. Estimation of global temperature trends: What's important and what isn't. Clim. Change 2010, 100, 59-69.

3. Böhm, R.; Jones, P.D.; Hiebl, J.; Frank, D.; Brunetti, M.; Maugeri, M. The early instrumental warm-bias: a solution for long central European temperatures series 1760-2007. Clim. Change 2010, 101, 41-67.

4. Oke, T.R. Initial Guidance to Obtain Representative Meteorological Observations at Urban Sites, Instruments and Methods of Observation Program; IOM Report No. 81, WMO/TD 1250. World Meteorological Organization: Geneva, Switzerland, 2004.

5. Stewart, I.D. A systematic review and scientific critique of methodology in modern urban heat island literature. Int. J. Climatol. 2010, in press. 
6. Fujibe, F. Detection of urban warming in recent temperature trends in Japan. Int. J. Climatol. 2009, 29, 1811-1822.

7. Ren, G.Y.; Chu, Z.Y.; Chen, Z.H.; Ren, Y.Y. Implications of temporal change in urban heat island intensity observed at Beijing and Wuhan stations. Geophys. Res. Lett. 2007, 34, L05711:1-L05711:5.

8. Ren, G.Y.; Zhou, Y.; Chu, Z.; Zhou, J.; Zhang, A.; Guo, J.; Liu, X. Urbanization effects on observed surface air temperature trends in North China. J. Clim. 2008, 21, 1333-1348.

9. Arnfield, A.J. Two decades of urban climate research: a review of turbulence, exchanges of energy and water, and the urban heat island. Int. J. Climatol. 2003, 23, 1-26.

10. Parker, D.E. Urban heat island effects on estimates of observed climate change. Wiley Interdiscip. Rev. Climate Change 2010, 1, 123-133.

11. Parker, D.E. Large-scale warming is not urban. Nature 2004, 432, 290-290.

12. Parker, D.E. A demonstration that large-scale warming is not urban. J. Clim. 2006, 19, 28822895.

13. Peterson, T.C. Assessment of urban versus rural in situ surface temperatures in the contiguous United States: no difference found. J. Clim. 2003, 16, 2941-2959.

14. Jones, P.D.; Lister, D.H. The Urban Heat Island in Central London and urban-related warming trends in Central London since 1900. Weather 2009, 64, 323-327.

15. Wilby, R.L.; Jones, P.D.; Lister, D.H. Decadal variations in the nocturnal heat island of London. Weather 2010, submitted.

16. Karl, T.R.; Hassol, S.J.; Miller, C.D.; Murray, W.L., Eds.; Temperature Trends in the Lower Atmosphere: Steps for Understanding and Reconciling Differences. A Report by the Climate Change Science Program and Subcommittee on Global Change Research, Washington, DC, USA, 2006. Available online: http://www.climatescience.gov/Library/sap/sap1-1/finalreport/default.htm (accessed on 6 June 2010).

17. Mears, C.A; Wentz, F.J. The effect of diurnal correction on satellite-derived lower tropospheric temperature. Science 2005, 309, 1548-1551.

18. Christy, J.R.; Norris, W.B.; Spencer, R.W.; Hnilo, J.J. Tropospheric temperature change since 1979 from tropical radiosonde and satellite measurements. J. Geophys. Res. 2007, 112, D06102:1-D06102:16.

19. Rayner, N.A.; Brohan, P.; Parker, D.E.; Folland, C.K.; Kennedy, J.J.; Vanicek, M.; Ansell, T.J. Tett, S.F.B. Improved analyses of changes and uncertainties in sea surface temperature measured in situ since the mid-nineteenth century: The HadSST2 data set. J. Clim. 2006, 19, 446-469.

20. Thompson, D.W.J.; Kennedy, J.J.; Wallace, J.M.; Jones, P.D. A large discontinuity in the mid-twentieth century in observed global-mean surface temperature. Nature 2008, 453, 646-649.

21. Santer, B.D.; Wigley, T.M.L.; Boyle, J.S.; Gaffen, D.J.; Hnilo, J.J.; Nychka, D.; Parker, D.E.; Taylor, K.E. Statistical significance of trends and trend differences in layer-average atmospheric temperature time series. J. Geophys. Res. 2000, 105, 7337-7356.

22. Sutton, R.T.; Dong, B.; Gregory, J.M. Land/sea warming ratio in response to climate change: IPCC AR4 model results and comparison with observations. Geophys. Res. Lett. 2007, 34, L02701:1-L02701:5. 
23. Joshi, M.M.; Gregory, J.M.; Webb, M.J.; Sexton, D.M.H.; Johns, T.C. Mechanisms for the land/sea warming contrast exhibited by simulations of climate change. Clim. Dyn. 2008, 30, 455-465.

24. Small, C.; Cohen, J. Continental physiography, climate and the global distribution of human population. Curr. Anthropol. 2004, 45, 269-277.

(C) 2010 by the authors; licensee MDPI, Basel, Switzerland. This article is an open access article distributed under the terms and conditions of the Creative Commons Attribution license (http://creativecommons.org/licenses/by/3.0/). 